\title{
Diabetes in part-Aborigines of Western Australia
}

\author{
K.G.Stanton, V.McCann, M. Knuiman, I.J.Constable and T. Welborn \\ Departments of Medicine, Ophthalmology and Mathematics, University of Western Australia, Perth, Australia
}

\begin{abstract}
Summary. One thousand, two hundred and eighteen diabetic subjects living in and around country towns of Western Australia were screened for complications of diabetes. This population included 134 subjects of Aboriginal descent, who were compared with the Caucasoids taking part. In the Aboriginal group there was a greater porportion of Type 2 (non-insulindependent) diabetic patients, a relative female preponderance (69\% compared with 51\%) and a tendency to present at an earlier age of onset than their Caucasoid counterparts. Diabetic complications were at least as common in the Aboriginal
\end{abstract}

group as in the Caucasoid patients. Indeed, retinopathy within 10 years of onset of diabetes was more common in the Aborigines. Peripheral neuropathy was more prevalent in Aborigines treated by diet alone or oral hypoglycaemic agents than in Caucasoids. A much greater prevalence of proteinuria was an additional feature of the Aboriginal subgroup (29\% versus $4 \%$ ).

Key words: Aborigines, Caucasoids, diabetic retinopathy, proteinuria.
Diabetes is common in the Australian Aboriginal population, with reported prevalence rates between $10 \%$ and $20 \%$ [1-4]. This population consists of full-blood and part-Aborigines. The Western Australian population includes 31,000 subjects who acknowledge Aboriginal descent. In the more urbanized south-western region of the state, the Aborigines are almost entirely of mixed Aboriginal and Caucasoid origin. Full-blood Abori- gines live in the more isolated regions in the northern and eastern parts of Western Australia. In 1978 the Lions Save Sight Foundation of Western Australia and the Diabetes Research Foundation of Western Australia initiated a community-based survey of known diabetic subjects in rural towns of the southwest and central Western Australia. Most Aborigines in these areas are part-Aborigines, with a small number of full-bloods

Table 1. Characteristics of the population studied

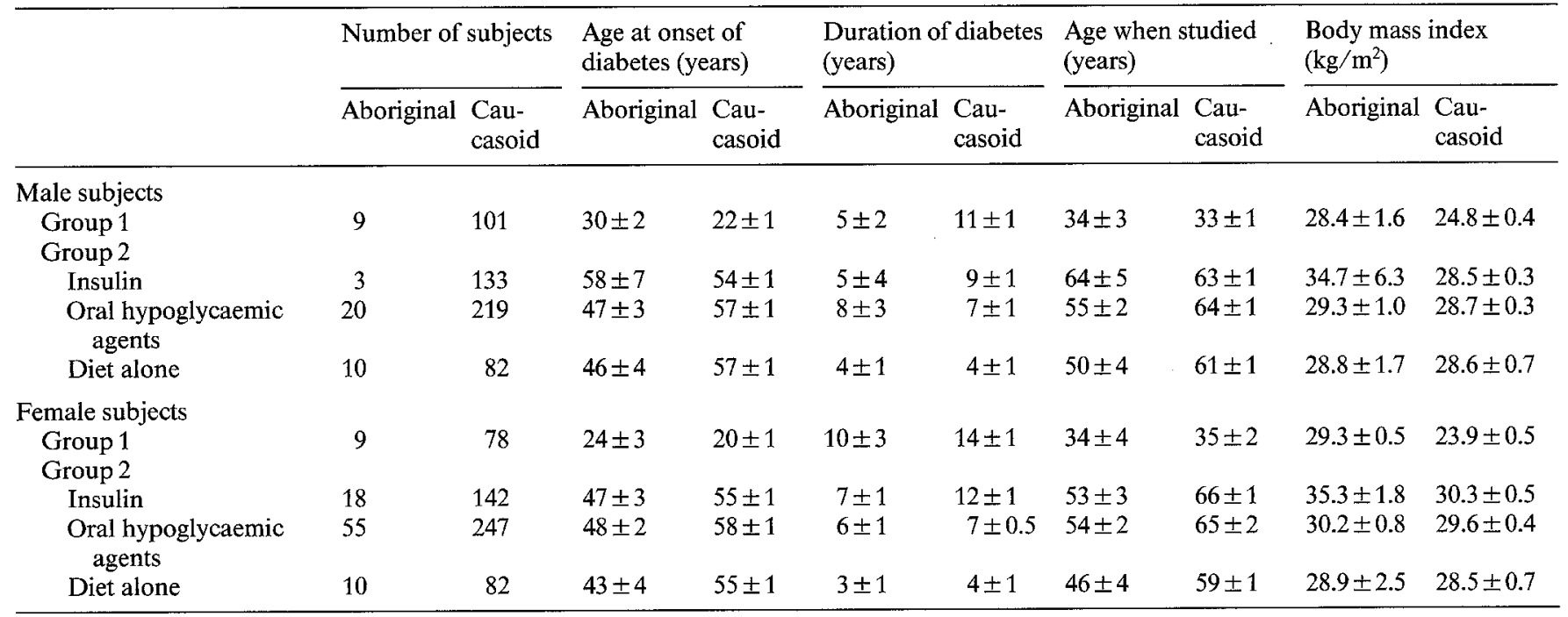

Results expressed where appropriate as mean \pm SEM 


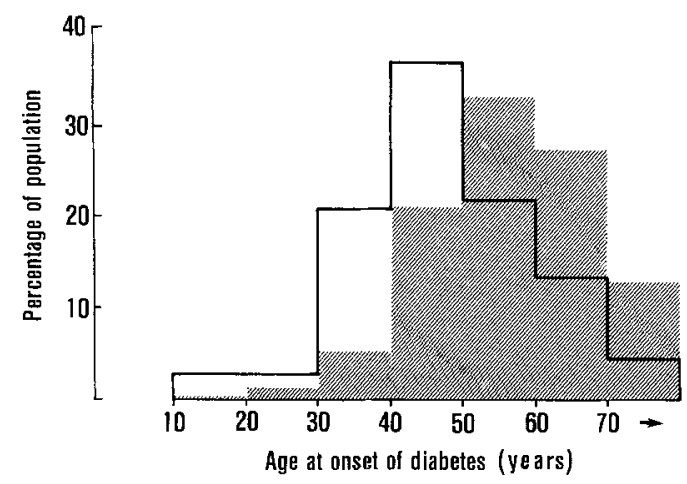

Fig. 1. Distribution of age at onset of diabetes in Aboriginal and Caucasoid populations studied (group 2). Aboriginal $(n=116) \square$; Caucasoid $(n=905) \square$

being included from the northern towns of Geraldton, Port Hedland and Kalgoorlie. The initial screening involved 1218 diabetic patients of whom 134 were of Aboriginal descent. The Aboriginal group has been examined in detail and compared with the diabetics of Caucasoid origin attending this survey. In this way we have attempted to define the clinical picture of diabetes in urbanized Aborigines and to clarify whether they are more or less prone to complications of diabetes than their Caucasoid counterparts.

\section{Subjects and methods}

\section{Subjects}

The population studied consisted of diabetic patients who volunteered to attend the survey (Table 1). It included about $70 \%$ of the estimated number of known diabetics in the region. The total population was divided into two groups. Group 1 was defined by clinical diabetes with onset before the age of 40 years, requiring permanent insulin therapy within 2 years of diagnosis. In this way juvenile-onset, insulin-dependent diabetic patients were separated from the rest of the population (group 2). Group 2 was a composite group consisting mainly of subjects with Type 2 diabetes. This group was sub-classified according to the type of treatment.

Participants in the survey were asked about their racial origin and then divided into Caucasoid and Aboriginal groups. The latter included all subjects claiming to be of Aboriginal descent. Most were part Aboriginal/part Caucasoid. Gene-dilution studies suggested that they were on the average approximately 50\% Aboriginal and 50\% Caucasoid (see Results).

\section{Methods}

The organization and screening methods have been described previously [5]. Briefly, the screenings were carried out by a team of ophthalmologists, physicians and para-medical personnel in collaboration with local medical authorities. Attempts were made to inform all known diabetic patients in the district. Ophthalmic examination included direct and indirect ophthalmoscopy, colour fundal photography but not fluorescein angiography. Retinopathy was divided into simple background, obstructive and proliferative. Obstructive retinopathy was characterized by blot haemorrhages, cotton wool spots and/or obliterated vessels.

A questionnaire providing information about the time of onset of diabetes, treatment regimen, frequency of hypoglycaemic episodes or ketoacidosis and the presence of complications of diabetes was completed by the patient and checked with a physician. It contained a series of questions from the London School of Hygiene questionnaire [6] used to define chest pain. Cardiovascular disease was said to be present if the subject had definite angina, or there was a past history of myocardial infarction. Claudication and stroke were also assessed by questionnaire and confirmed by the physician. People with macrovascular disease included subjects with one or more of the following disorders: cardiovascular disease, stroke and peripheral disease. Limited examination by the physician included blood pressure in the supine and erect positions, peripheral sensation, deep tendon reflexes and peripheral arterial pulses. Hypertension was defined by systolic blood pressure $\geqslant 160$ and/or a diastolic $\geqslant 100 \mathrm{mmHg}$, or treatment for hypertension at the time of the survey. Sensory neuropathy was defined as a symmetrical loss of sensation in the feet on clinical examination. Urine was tested for protein with Albustix (Ames, New York, USA) and a result $\geqslant 1 \mathrm{~g} / 1$ was considered significant proteinuria. Non-fasting blood and serum samples were taken for analysis for blood glucose, haemoglobin $\mathrm{A}_{1}\left(\mathrm{HbA}_{1}\right)$, serum creatinine, total serum cholesterol and the high density lipoprotein cholesterol fraction. Blood glucose and serum creatinine were determined by an automated glucose oxidase technique using an autoanalyser (Technicon SMAC II, Tarrytown, New York, USA). A microcolum [7] was used for $\mathrm{HbA}_{1}$ estimations. Total serum cholesterol was determined enzymatically and HDL cholesterol separately [8]. Height and weight were recorded and the body mass index calculated.

\section{Statistical analysis}

Multiple linear and logistic regression analyses were used to test whether there was significant racial difference between the two populations, after possible confounding variables had been taken into account. In addition the model reduction procedure was performed, beginning with the largest possible model and reducing until reductions were statistically significant [9].

\section{Results}

\section{Characteristics of the Aboriginal group}

The Aboriginal group included all subjects of Aboriginal descent, most of whom were part-Aborigines (Table 1). Gene-dilutional studies with red-blood-cell acid phosphatase (full-blood Aborigines assumed to be 100\% Type B) and properdin (full-blood Aborigines assumed to lack Type F) suggested a gene replacement rate of $50 \%$ and $69 \%$, respectively. Thus this population is approximately 50\% Aboriginal and 50\% Caucasoid when assessed by these genetic markers.

When the Aborigines and Caucasoids were compared, more females were present in the Aboriginal group. Sixty-nine percent of the Aborigines were female compared with $51 \%$ of the Caucasoid group. This sex difference was due to a greater proportion of female Aborigines with Type 2 diabetes.

Presentation and diagnosis of Type 2 diabetes often occurs at an earlier age in Aborigines than in Caucasoids. For instance, the mode of the distribution of age at onset of diabetes in group 2 subjects occurred a decade earlier in the Aborigines. As the statistical distribution of age of onset was similar in both groups there was no suggestion that the younger presentation of Aborigines was due to a subgroup within the Aboriginal pop- 
Table 2. Laboratory investigations and complications of diabetes

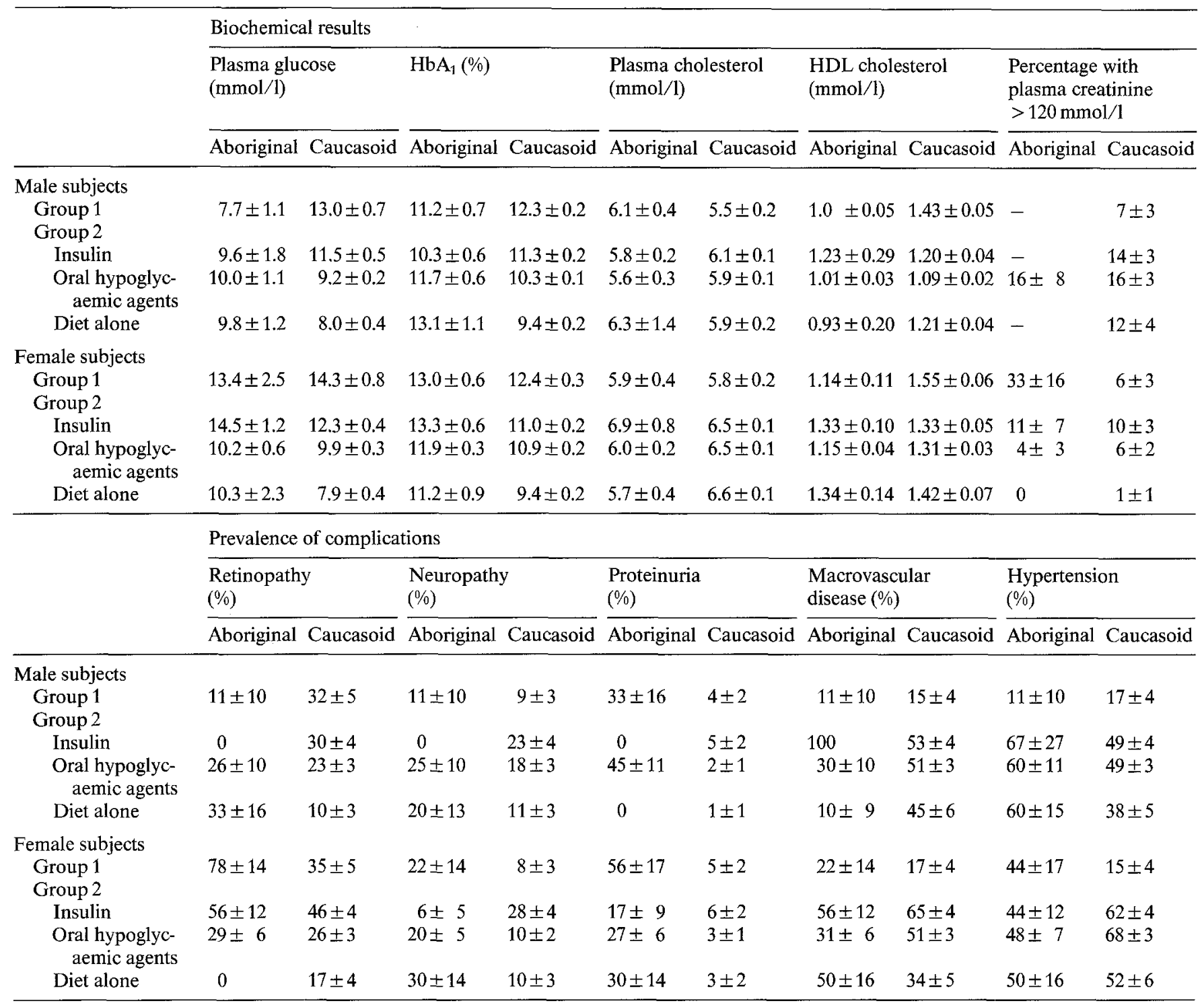

Results expressed as mean $\pm \mathrm{SEM}$

ulation characterized by an earlier age of onset (Fig.1). At the time of the survey the Aborigines tended to be younger and to have had diabetes diagnosed for a shorter period (Table 1).

Obesity was more common in the Aboriginal group (Table 1). Factors other than race which influenced obesity included sex, age and type of treatment. When differences in these factors were taken into account, there was no significant difference in the degree of obesity between group 2 Aborigines and Caucasoids treated with diet alone or diet and oral hypoglycaemic agents. Only Aborigines in group 2 who received insulin were more obese than their Caucasoid counterparts. In both racial groups females were more obese than males and the degree of obesity increased with age. Similar trends were present in group 1, but the small number of Aborigines in this group limited interpretation of the data.

\section{Type of diabetes}

Type 2 diabetes was more common in the Aborigines than the Caucasoid group. Only $13 \%$ of the Aborigines were classified as having Type 1 (insulin-dependent) diabetes compared with $17 \%$ of Caucasoids. Within group 2, 18\% of Aborigines received insulin compared with $30 \%$ of the Caucasoid patients. These differences in therapy suggest that Type 2 diabetes accounted for the increased prevalence of diabetes in this Aboriginal group.

\section{Investigations}

Plasma glucose and glycosylated haemoglobin (Table 2): Relatively greater hyperglycaemia, as estimated by a non-fasting blood glucose and a $\mathrm{HbA}_{1}$, was a feature of the Aborigines in group 2. The mean $\mathrm{HbA}_{1}$ in female 
Caucasoids in group 2 was $11 \%$ compared with $12 \%$ in female Aborigines. This difference was similar for all treatments, in both sexes, except in the subgroup of males on insulin. However there were only three male Aborigines on insulin in group 2. For plasma glucose the racial difference was statistically less significant because measurements were more variable. In contrast, in group 1 these measures of hyperglycaemia were similar in Caucasoids and Aborigines.

Plasma lipids: There were minor differences in total plasma cholesterol which varied between treatment groups. Aborigines tended to have slightly lower total plasma cholesterol levels than their Caucasoid counterparts (Table 2); however, this reached statistical significance only in the group treated with diet and/or oral hypoglycaemic agents. The HDL cholesterol fraction was lower in the Aborigines (group $1 \chi_{(2)}^{2}=14.2, p<$ 0.01 ; group $2 \chi_{(2)}^{2}=11.9, p=0.07$ ). In female Aborigines the mean was 1.20 , compared with 1.37 in female Caucasoids. This difference was present in both sexes, in both groups and in all treatment modes within group 2, except in males on insulin. As noted above comparisons were limited in this subgroup by the small number of subjects.

\section{Complications of diabetes (Table 2)}

Retinopathy: Retinopathy was at least as common in Aborigines as in Caucasoids. For the comparison to be valid, differences in duration as well as sex ratio and treatment must be taken into account. As the adjustment for duration is different for each race and sex, fitted rates for 2 and 20 years' duration were calculated. At 2 years' duration, the prevalence rate in Aborigines was approximately $10 \%$ higher than in Caucasoids and this diminished with time, being insignificant after 10 years. Similar trends were present in group 1. The type of retinopathy was not analysed in detail as the Aboriginal group was too small to allow correction for variables including duration, sex and treatment mode. Overall, obstructive retinopathy was more common in the Aboriginal subjects $(12 \%$ versus $8 \%)$.

Proteinuria and raised creatinine levels: The prevalence of proteinuria was greater in the Aborigines (29\%) than in Caucasoids $(4 \% ; p=0.01)$ in all clinical groupings irrespective of the type of treatment. In contrast, the frequency of renal impairment was similar in the two racial groups.

Macrovascular disease: There was no significant difference in the prevalence of macrovascular disease between the Aboriginal and Caucasoid subjects, even after adjusting for the age effect of the younger Aboriginal subjects.
Hypertension: More Aborigines than Caucasoids were hypertensive at the time of the survey. Fitted regression lines demonstrated the higher systolic blood pressure recorded in group 2 Aborigines of both sexes after taking age into account. However more Caucasoids than Aborigines were receiving treatment for hypertension and after inclusion of these subjects in the hypertension subgroup, only in males was the prevalence of hypertension higher in Aborigines. After adjustment for age and obesity, hypertension was still $20 \%$ more prevalent in male Aborigines than in male Caucasoids. At 60 years of age and a body mass index of 31, the adjusted prevalence rate for hypertension was $70 \%$ in male Aborigines taking oral hypoglycaemic agents and 49\% in the corresponding Caucasoid group.

Sensory neuropathy: Sensory neuropathy was more common in the Aboriginal population. Duration and age at onset of diabetes were important determinants for sensory neuropathy. After adjusting for these variables the Aborigines on diet alone and diet plus oral hypoglycaemics had more neuropathy than their Caucasoid counterparts $\left(\chi_{(2)}^{2}=20.2, p=0.01\right)$. This racial difference was absent in subjects receiving insulin. Although the Aborigines generally had poorer control than Caucasoids there was no correlation between $\mathrm{HbA}_{1}$ and prevalence of neuropathy in the different treatment subgroups of the Aboriginal subjects.

\section{Discussion}

Although the prevalence of diabetes in Aborigines cannot be determined accurately by this type of study, the findings do suggest that diabetes is more prevalent in this racial group. The Western Australian Government census of Aborigines in 1983 (D. Hicks, personal communication) found there were 1,239 Aborigines in this region, in an age range similar to that of the Aboriginal subjects in the diabetic survey. Our study population constituted $11 \%$ of the total age-matched Aboriginal population, but the true prevalence of diabetes must be greater as not all known diabetics attended the survey.

Subject self-selection did not create any obvious bias in the Caucasoid subjects. In age distribution, sex ratio and duration of diabetes this group was similar to a population of Caucasoid diabetic subjects studied in Newcastle, Australia [10]. As there is no similar information for Aborigines, we cannot eliminate bias in that subgroup; however the method of recruitment for the survey was identical for all subjects.

Diabetes is a feature of urbanized subjects from many racial groups [11-13]. Both genetic and environmental factors may contribute. Obesity alone does not explain the greater prevalence of diabetes in this partAboriginal population. A genetic factor may be important, as the prevalence is much greater than that in Cau- 
casoid subjects from this region [14] but less than the $17 \%$ prevalence observed by Bastian [3] in full-blood tribal Aborigines from the Kimberley region of northern Western Australia. Racial admixture has been correlated with the prevalence of diabetes in Mexican Americans [15].

Before comparing the prevalence of diabetic complications in the two racial groups, adjustments were made for population differences likely to affect the outcome. For instance, the Aboriginal subjects included more females, were younger at the time of examination and had diabetes for a shorter time. After allowing for these variables and the mode of treatment, all complications of diabetes were as frequent, or more frequent, in the Aboriginal diabetics.

Duration of diabetes is the major risk factor in diabetic retinopathy $[16,17]$. When Aborigines and Caucasoids were compared at different periods of diagnosis during the first 10 years, diabetic retinopathy was more common in the Aborigines. Factors which may have contributed to this difference include poorer control of hyperglycaemia and hypertension in the Aboriginal patients. These factors may also influence the type of retinopathy, obstructive retinopathy probably being more prevalent in Aboriginal subjects. However, the small numbers of Aboriginal patients within particular subgroups with retinopathy prevented any conclusions from this study.

Wise et al. [1] also detected proteinuria in nearly onethird of Aboriginal diabetic subjects. Diabetic nephropathy is unlikely to be the major cause as proteinuria in the Aboriginal patients did not correlate with retinopathy or with duration or type of diabetes. In 34 of the Aboriginal subjects from Geraldton, whose urine was studied, there was no association between urinary tract infections or abnormal urinary sediment and proteinuria. However proteinuria was not a benign abnormality. It was associated with impairment of renal function and hypertension. Fifteen percent of Aborigines with proteinuria, but only $2 \%$ of those without, had a plasma creatinine level greater than $120 \mathrm{mmol} / 1$. Thirty-one percent of the proteinuric Aborigines were hypertensive compared with $23 \%$ of the remainder.

Risk factors for cardiovascular disease were common in this Aboriginal group. Male Aborigines were more likely to have hypertension and were more hypertensive at the time of examination than were male Caucasoids. Those receiving insulin were more obese and Aborigines in group 2 had a worse lipid profile with reduced HDL cholesterol and increased total cholesterol levels. In addition greater hyperglycaemia, as measured by a $\mathrm{HbA}_{1}$ may have increased the risk. In spite of this worse risk profile, we were not able to document any difference in the prevalence of cardiovascular disease, and macrovascular complications generally, between Aborigines and Caucasoids. This may be due to the insensitivity of our questionnaire. A more detailed examination including ECG and chest X-ray might have pro- duced a different result as ECG abnormalities are very common in diabetic Aborigines [3, 18].

Among group 2 subjects who were treated with diet alone or diet and/or oral hypoglycaemic agents, neuropathy was more prevalent in Aborigines. As this group included the majority of Aboriginal subjects, it is of particular significance. Surprisingly this association was not present in those treated with insulin, whether in group 1 or 2 . This difference could not be explained by the degree of hyperglycaemia assessed as $\mathrm{HbA}_{1}$ nor did treatment itself seem a likely explanation as the trend with mode of treatment in the Aborigines was converse to that in Caucasoids. Alcohol intake showed large regional differences which made comparison between groups difficult, but it did not appear to correlate with sensory neuropathy. Thus a relatively high prevalence of sensory neuropathy in Type 2 Aboriginal diabetics had no obvious explanation.

Diabetes is a major health problem in urbanized Aborigines. The study has indicated that diabetes is common in Aborigines and often associated with complications. A relatively high prevalence of Type 2 diabetes was a feature. Although Aboriginal diabetics often present at an earlier age and include more female subjects than do Caucasoids, there is no evidence that they contain a subgroup with a different type of diabetes. Diabetes is not a benign disorder in Aborigines, who develop as least as many complications as Caucasoid subjects. Aboriginal diabetics were also susceptible to renal disease, and perhaps to hypertension. If we can elucidate the environmental factors which aggravate a possible genetic susceptibility to diabetes then steps could be taken to reduce the health problem which has been reflected in this survey.

Acknowledgements. We are grateful to J.Masserei for measurement of biochemical parameters, R.Davis for $\mathrm{HbA}_{1}$ estimations and J. Oversby for typing the manuscript.

\section{References}

1. Wise P, Edwards F, Thomas D, Elliott K, Hatcher L, Craig K (1970) Hyperglycaemia in the urbanized Aborigine. The Davenport study. Med J Aust 28: 1011-1006

2. Finley-Jones R, McComish M (1972) Prevalence of diabetes mellitus in Aboriginal lepers. Med $\mathbf{J}$ Aust 2: 135-137

3. Bastion $\mathrm{P}(1978)$ Coronary heart disease in tribal Aborigines - the West Kimberley survey. Aust NZ J Med 9: 284-292

4. Wise P, Edwards F, Craig R, Evans B, Marchland J, Sutherland B, Thomas D (1976) Diabetes and associated variables in the South Australian Aboriginal. Aust NZ J Med 6: 191-196

5. Constable I, Welborn T, Cooper R, McCann V, Stanton K, Greer D, Bastion P (1980) Symposium on medical ophthalmology medical correlates and diabetic retinopathy screening. Trans Ophthalmol Soc, UK 100: 78-81

6. Rose B, Blackburn H (1968) Cardiovascular survey methods WHO Monograph Series 56, Geneva

7. Davis R, Nicol D (1978) A rapid simplified method for the routine measurement of glycosylated hacmoglobin. Lancet 2: 250-251

8. Burstein M, Samaille J (1960) Rapid estimation of cholesterol 
bound to alpha and beta lipoproteins of serum. Clin Chim Acta 5: 609

9. Alvey W, Barfield C, Baxter R, Gower J, Drzanowski W, Lane P, Leech P, Nelber J, Payne R, Thelps K, Roger C, Ross G, Simpson H, Todd A, Wedderburn R, Wilkinson G (1977) GENSTAT: a general statistical programme. Rothamstead Experimental Station, Rothamstead, UK, pp 781-786

10. Mitchell P (1980) Prevalence of diabetic retinopathy: study of 1300 diabetics from Newcastle and Hunter Valley. Aust J Ophthalmol 8: 241-246

11. Zimmet P, Arblaster M, Thomas R (1978) The effect of westernization on native population. Studies on a Micronesian community with a high diabetes prevalence. Aust NZ J Med 8: 141-146

12. Zimmet P, Ainee S, DeBoer W, Faaiuso J, Whitehouse S (1981) The prevalence of diabetes in the rural and urban Polynesian population of Western Samoa. Diabetes 30:45-51

13. Cruz-Vidal M, Costas R, Garcia-Palmeiri MR, Hertsmark E, Sorlie PD (1979) Factors related to diabetes mellitus in Puerto Rican men. Diabetes 28: 300-307

14. Welborn T, Cullen K, Curnow D, McCall M, Stenhouse M, Wearne J (1968) Diabetes detected by blood sugar measurement after a glucose load: report from the Busselton survey. Med J Aust $2: 778-782$
15. Gardner W, Stern M, Heffner S, Gaskill S, Hazuda H, Relethford J, Eifler C (1984) Prevalence of diabetes in the Mexican American. Diabetes 33: 86-92

16. Burbitt A, Caird F, Draper G (1968) The natural history of diabetic retinopathy. AJ Med Nov Series 37:303-317

17. Rate R, Knowler W, Morse H, Bonnell M, McVey J, Chervenak C, Smith M, Pavanich G (1983) Diabetes mellitus in Hopi and Navajo Indians. Prevalence of microvascular complications Diabetes 32: 894-899

18. Edwards F, Wise P, Thomas D, Marchland J, Craig R (1976) Blood pressure and electrocardiographic findings in the South Australian Aborigines. Aust NZ J Med 6: 187-205

Received: 22 March 1984

and in revised form: 5 November 1984

Dr. K.G.Stanton

Diabetic Clinic

Royal Perth Hospital

Wellington Street

Perth 6000

Western Australia 